\title{
Die verhaal as mitiese vraagstelling: die verhaalkuns van Henriette Grové
}

\author{
Heilna du Plooy \\ Departement Afrikaans en Nederlands \\ Potchefstroomse Universiteit vir Christelike Hoër Onderwys \\ POTCHEFSTROOM
}

\begin{abstract}
Story as mythical questioning: The narrative art of Henriette Grové

Henriette Grove's stories are mostly concerned with the nature and meaning of human experience, especially human suffering. In this article an effort is made to characterize these stories, indicating the relation between the stories and a way of thinking that is primarily concerned with metaphysical, mythical and religious issues. Texts like In die kamer was 'n kas and Die kêrel van die Pêrel and some short stories are examined to find indications of the underlying vision of man from which the stories generate. Special attention will be given to focalization in the stories, indicating the need to extend the meaning and use of the term so that textual as well as extratextual modal relations can be described. These relations may provide an indication of the vision of man which is faroured by the "abstract author" and which in this case seems to encompass much more than mere ideological thought patterns. Grove's stories posit questions which, being mythical questions, can only be answered in a religious manner. The stories do not provide solutions to the problematic nature of experience and suffering, but insist on asking the type of questions with which religion concerns itself.
\end{abstract}

\section{Inleiding}

In hierdie artikel word die verhaalkuns van Henriette Grové bespreek spesifiek na aanleiding van tema en visie om sodoende 'n stelling te probeer maak oor die aard van haar werk. Die probleemstelling word geformuleer na aanleiding van sekere reaksies van resensente op Grové se jongste werk, In die kamer was 'n kas (1989), en daama word die plek van die tema in 'n teks kortliks beredeneer. Grové se tematiek word kortliks verken en in verband gebring met uitsprake van die skryfster self. Deur 'n kritiese kyk op die bestaande teorie oor fokalisasie wil ek enkele opmerkings maak oor die visie in die laaste twee werke van Henriette Grové en daana probeer ek 'n konklusie formuleer aangaande die betrokke werke.

Koers 61(t) 1996:397-410 


\section{Lesersingesteldheid en tema in die resepsie van 'n teks}

Die roman In die kamer was ' $n$ kas verskyn in 1989. In hoofsaak stem die kritici saam oor die meriete van die werk, maar waar daar verskille voorkom, is dit duidelik die resultaat van verskillende teoretiese en ideologiese vertrekpunte. Die waardering vir die roman word as't ware getemper en ondermyn deur ernstige vrae oor die relevansie van 'n roman oor die lyding van wit Afrikaanse mense in 'n Suid-Afrika wat (juis in 1989) in 'n fase van politieke hoogspanning staan. Die sterkste kritiek word uitgespreek deur Gerrit Olivier (1990). Hy sien die roman as ongeskakeerd pessimisties en behep met bloed en lyding. Hy suggereer dat daar ' $n$ diskrepans bestaan tussen die problematiek in die werk en die uitbeelding daarvan en beskryf dit as 'n werk met "Bybelse resonansies sonder Bybelse troos" (Olivier, 1990). Vir 'n skryfster met die reputasie van Grove is so 'n uitspraak byna 'n soort aanklag en dit vra on deegliker ondersoek te word.

By nadere beskouing is dit vir my opvallend dat die verskillende reaksies almal primêr met tematiese kwessies gemoeid is. Hoewel die styl van die roman enersyds gekomplimenteer word en andersyds gekritiseer word, lê die kem van die uitsprake telkens op die vlak van die onderwerp, die storie (inhoud, gegewe) en die tema, 'n bepaalde interpretasie van die onderwerp. 'n Mens kan ook aantoon dat die invalshoek duidelik bepaal word deur die leeskonteks, die intertekstuele ruimte waarbinne gelees word (vgl. Du Plooy, 1990): in hierdie geval 'n laat twintigste-eeuse wêreld, 'n land deur politieke drama oorheers met al die ideologiese, sosiale, ekonomiese, historiese en (les bes gebrek aan!) religieuse intertekste wat saampraat. Die teoretiese en kritiese uitsprake van die resensente word in hierdie spesifieke periode hoofsaaklik beinvloed deur die ideologies-bepaalde intertekstuele ruimte wat lei tot bepaalde interpretasies van die teks en die tema van die teks.

Ek wil hierdie uiteensetting gebruik as vertrekpunt om te probeer aantoon dat Grové se verhale juis nie tydgebonde is of wil wees nie en dat dit hier gaan om 'n bepaalde toonaard waarin gedink en geskryf word, 'n toonaard wat radikaal verskil van die kontemporêre literêre modestyl wat veral onderwerp en tema betref.

\section{Die plek van die tema in 'n teks}

Terwyl dit mag voorkom asof ' $n$ mens jou met iets te basies besig hou as jy gaan kyk na die onderwerpe en temas van tekste (en ek gee dadelik toe dat dit inderdaad heel dikwels op nalewe wyse gedoen word), is dit tog waar dat 'n mens nooit lees sonder dat tematiese kwessies 'n deurslaggewende rol speel nie. In 'n boek met die titel Thematic Criticism praat Werner Sollors (1993:xiii) van "the widespread, yet undeclared 'thematic' practitioners who do not claim (or who openly disclaim) affinities with "thematology"'. Daar word betoog dat 'n 
bemoeienis met tematiek gerig is op "the things which (literature) is significantly and importantly about" (Brinker, 1993:21). Vanselfsprekend gaan die beoordeling van ' $n$ werk se tematiese belang of betekenis aflang van die konteks (interteks) waarbinne gelees word en van die invalshoek van die ontvanger, soos wat inderdaad in die geval van Henriette Grove se werk aangetoon kan word (Du Plooy, 1991).

In my betoog aanvaar ek die onderskeid tussen onderwerp en tema soos gefornaliseer deur Beardsley (1958), naamlik dat onderwerp dui op die saak waaroor die teks handel en tema op die moontlike betekenisse wat aan die uitbeelding van ' $n$ bepaalde onderwerp geheg kan word deur ontvangers. Die tema word selde indien ooit eksplisiet in ' $n$ teks verwoord en is gewoonlik die resultaat van ' $n$ bepaalde interpretasie sodat 'n mens fyner kan onderskei tussen verskillende fasette van die teks: "(the) distinction ... between what a discourse is rhetorically about and that which it may be taken to be referentially about when read metaphorically" (Brinker, 1993:27).

In 'n verhalende teks word 'n bepaalde "wêreld" talig tot stand gebring, maar dié wêreld hou verband met herkenbare strukture, konkreet of abstrak, in die werklike wêreld waarin die leser leef. Die tekstuele wêreld word egter geïnterpreteer en kan vir die leser, aflangende van sy konteks, sinvol en relevant wees. Die kern van die interpretasie is die tema wat die leser uit die teks abstraheer.

In die interpretasie van 'n bepaalde teks speel die tema dus 'n baie belangrike rol ondat die potensieel sinryke verband met die werklikheid in die tema setel en die teks so vir die leser relevant en betekenisvol kan word. Dit word moontlik "in recognizing theme as an interesting meeting point of texts, which proves fruitful in creating the context in which to interpret a work (at least partially) ... (Theme) ... unifies a large or conspicuous or important portion of these components relative to a specific descriptive interpretation of the work's 'world' and language" (Brinker, 1993:23)

Die belangrikheid van hierdie ontmoetingsplek tussen tekstuele wêreld en leserswerklikheid is vanselfsprekend omdat die leser juis daarin bewus word van die belang, relevansie en sin van die teks vir die leser as mens in 'n spesifieke werklikheid.

Identification of themes is a necessary condition for an emotional response to a literary work and its poetic world. But a referential reading of fiction implies more than that. It implies seeing some conspicuous elements of its poetic world as models of structures of the real world, and this must divert our attention from the poetic world itself toward a poetic vision of some nonpoetic reality. We ascribe different telcologies to different motives for our reading them. Therefore we are interested in actualizing the virtual references to the real world contained in the theme only when we have in 
Die verhaal as muticse vraagstelling: die verhaalkums van Henriette Grove

mind a specific cognitive teleology of the work or of our reading of it

(Brinker, 1993:30).

Die relevansie van 'n werk word dus bepaal deur die betekenis van wat in die teks gelees word. En dit gaan hier juis nie om 'n naïewe referensiële siening van 'n teks nie, maar om die komplekse verhouding tussen die talige fiksionele wêreld van die teks en die indirekte verband met die werklikheid en werklikheidsiening van die leser.

Brinker (1993:30) stel dit so: “... the fictional world cuts its referential ties to the world on its linguistic level. In order to resume them on its representational level we require an interpretive motive. This motive may be supplied by the work itself or by a chosen interpretative context"

Die interpretatiewe motief vir die aanvanklike resensente van byvoorbeeld In die kamer was 'n kas is hoofsaaklik bepaal deur die ideologiese atmosfeer van die jaar 1989. Maar is dit die enigste motief of impuls wat interpretasies van hierdie roman, en ook terugskouend van Grové se vroeër werk kan genereer?

\section{Belangrike temas in die verhaalkuns van Henriette Grové}

Vir die doel van hierdie artikel beperk ek my tot die laaste twee werke van Henriette Grové, naamlik die novelle Die kêrel van die Pêrel en die roman In die kamer was ' $n$ kas. Die rede hiervoor is dat ek hierdie twee werke as verteenwoordigend en selfs as die kulminasie van die tematiek van haar hele oeuvre beskou.

In hierdie twee werke vind 'n mens, net soos in die kortverhale, 'n byna ongenadige deurskouing van die onderwerpe waaroor die verhale handel. In Die kêrel van die Pêrel gaan dit om die kwessie van waarheid en leuen, en die implisiete vraag in die novelle is: Hoe kan 'n mens leer of probeer om die verskriklikheid van die waarheid en werklikheid te hanteer?

Die hoofkarakter, Elwiena, probeer op verskillende maniere vrede maak met die dinge in haar lewe waarvan sy niks hou nie. Sy probeer dit ignoreer en in 'n droomwêreld wat uit leuens bestaan, opgaan. Dit het vir haar baie slegte gevolge. Dan besluit sy om die werklikheid net so te aanvaar, om niks meer te vra as die gewone nie, om die waarheid van elke onaangenaamheid met lydsaamheid te verduur. Uiteindelik besef sy dan dat ' $n$ mens dit nodig het om soms agter "leuens" te skuil, om skuiling te soek teen die onherbergsame werklikheid in woorde en drome wat regtig net leuens is, maar inderdaad lewensnoodsaaklike leuens.

In die roman In die kamer was 'n kas word drie verhale vertel van drie groepe mense wat niks met mekaar te make het nie, behalwe dat hulle almal blootstaan 
aan die teisteringe van die lewe. Petrus van Deventer trek saam met sy ouers in die jare voor die Groot Trek na die bimneland van Suidelike Afrika. Sy jeugjare word gevul met die een ontbering na die ander wat die gesin, en veral die moeder, beleef. Vir Petrus is 'n tuiste, 'n plek van sy eie en die behoefte daaraan om gevestig te wees so belangrik dat hy trou met 'n vrou wat grond besit al het hy haar glad nie lief nie. Hierdie vrou, 'n onaantreklike mens, onvrugbaar en met ' $n$ spraakgebrek, weet haar lewe lank dat haar man haar nie liefhet nie. Die tweede verhaal gaan oor Marta Koorts, 'n vrou in haar vroeë veertigerjare tydens die eeuwending na die twintigste eeu. Sy verloor haar goeie oordeel uit liefde vir 'n man en haar hele gesin word daardeur in ongeluk gedompel. Die laaste verhaal gaan oor twee vroue in die laaste helfte van die twintigste eeu. Hulle is die slagoffers van huweliksontrou en -ongeluk in twee opeenvolgende generasies en al hulle rykdom en voorregte, hulle verfyndheid en kunssinnigheid kan hulle nie van persoonlike smart vrywaar nie.

Die band tussen die drie verhale is inderdaad die implisiete vraag na die sin van lyding en veral die eksistensiële vraag: hoe gemaak met die syn, met dit wat gewoon is?

Tematies gaan dit dus in die twee werke om moeilike kwessies soos die onontwarbaarheid van waarheid en leuen (Dic kêrel) en die gevoel van die mens dat hy voortdurend magteloos en weerloos blootstaan aan lyding (In die kamer). Dit gaan ook oor die mens se stryd om die lewe te hanteer, sy dikwels byna onbeholpe pogings om staande te bly, maar dit gaan ook oor die moed en selfs verbetenheid waarmee sommige mense hierdie stryd stry.

Die vraag wat egter nie omseil kan word nie, is: Waarom bly die skryfster by sulke onderwerpe en sulke temas? Is sy die uiteindelike smartvraat? Is sy die prototipe van die Calvinistiese verheerliking van lyding?

\section{Poëtika}

Die poètika van 'n skrywer is nie altyd ewe relevant as ' $n$ mens die werke van die skrywer probeer verstaan nie. Die moontlikheid bestaan immers dat die skrywer iets glo oor die literatuur en die lewe en dit probeer oordra, maar in sy poging faal. Verder is die intensie van die outeur geen beperking of selfs riglyn vir die dikwels eiesinnige moderne interpreterende leser nie.

Die visie van die skrywer op die lewe en op sy taak as kunstenaar is egter tog ook ' $n$ relevante interteks wat gewis vir bepaalde lesers interessant en selfs belangrik kan wees. Vir my het daar inderdaad boeiende parallelle na vore gekom tussen Grové se uitsprake en haar werk. 


\section{1 'n Onafwendbare verloop vir' $n$ bepaalde verhaal}

In 'n gesprek met Elize Botha (opgeneem in Gesprekke met skrywers 3:62) praat Henriette Grové onder meer oor die populêre verhale wat sy geskryf het: "Jy sien wel in dat daardie probleem of daardie situasie waaruit jy jou verhaal laat ontstaan, eintlik dwingend op 'n bepaalde manier opgelos moet word, maar dan pleeg jy verraad teenoor dié wéét ..." want die populêre verhaal word geskryf om die leser te plesier. Hierdie gedagte, dat daar naamlik 'n onafwendbare verloop vir 'n bepaalde verhaal of probleem is, bly in haar uitsprake terugkeer. Sy voel haar selfs tot satire aangetrokke omdat sy soek na "iets om die flertse en behangseltjies weg te vat" (Gesprekke, 3:62).

Hierdie opvatting kom in 'n interessante gedaante na vore in Die kêrel van die Pêrel. In die verhaal bevind dr. Brink hom in 'n onmoontlike posisie omdat hy van die oortreding van die etiese kodes van medici verdink word. Die spontane en opregte aangetrokkenheid tussen Brink en Elwiena word egter oortuigend uitgebeeld sodat dit duidelik is dat Brink tussen hierdie oorweldigende liefde en sy eie etiese kode verskeurd staan. Daar word in die verhaal nie 'n maklike oplossing aangebied nie, en die verteller betrek die leser by die problematiek: "Maar Stefaans Brink se uiteinde bly problematies" (p. 91).

In 'n tipies postmodernistiese verteltrant voer die verteller dan 'n lang gesprek met haar pa waarin sy haar voorneme om 'n karakter selfmoord te laat pleeg beredeneer (p. 93). Die motivering vir die verskriklike daad van selfmoord wat die verteller eindelik aanbied, is dat dit onafwendbaar is dat hierdie bepaalde man selfmoord sou pleeg in hierdie omstandighede. Dit kan nie anders waar wees nie, en net hierdie een waarheid sou in die verhaal die waarheid kon wees. Hoe erg of skokkend, selfs onaangenaam dit is on dit te vertel en vir die leser om dit te lees, dit moet juis net so gebeur. En die skrywer en die leser moet 'n manier vind om die lewe te hanteer, net soos die karakters en mense in die werklikheid wat dinge beleef.

\subsection{Die voortgang van tyd}

Grové maak in dieselfde gesprek (Gesprekke 3:65) die stelling dat die voortgang van tyd haar toenemend boei en nie meer die verrassende patroonmatigheid van 'n enkele dramatiese gebeurtenis nie: "Ek wil nou liewer sien waarheen dit gaan; of liewer, ek sou wou wys hoe dinge maar aan en aan gaan, jy kan daar baie min aan doen ... die onherroepelikheid, die onverbiddelikheid van die voortgang van die tyd." In die voortgang van tyd en in ontwikkeling is daar nie noodwendig verbetering nie, en gewis ook nie altyd hoop nie. En dit is die saak wat haar boei, omdat dit so kwellend is. 
Dat die mens steeds vasgevang bly in die onvolkomenheid van sy bestaan, staan deurgaans voorop in In die kamer was 'n kas. Na 'n honderd jaar van ontwikkeling en vooruitgang op materiële gebied, nadat mense gevestig en bemiddeld is, geleenthede het, hulle talente kan ontwikkel en ontgin, bly mense uitgelewer aan hulle eie emosionele willekeur en die verwoestende gevolge daarvan. Marta Koorts is so eensaam dat sy 'n nikswerd man liefkry, Charlotte het haar pa se ontrouheid en haar ma se dood beleef en moet dan weer sien hoe haar eie man op haar halfsuster verlief raak. Marta moet uiteindelik die volle wete van wat gebeur het in die oë kyk en verder leef en Charlotte ook.

\subsection{Die soeke na die sin en waarheid van dinge}

Die skryfster erken dat sy nuuskierig is, dat sy dinge wil weet en wil ken (Gesprekke, 3:69). En hierdie uitspraak kan meer as duidelik in verband gebring word met die vertellersfigure in Die kêrel en In die kamer. In Die kêrel is die verteller deurgaans aan die bespiegel, aan die redeneer, oor wat om te vertel en hoe oun te vertel: die skryf van die verhaal word (eg postmodernisties) net so ' $\mathrm{n}$ probleem as die storie, die verhaalinhoud self. Die verteller in In die kamer vertel hoe sy as kind deur die weerkaatsende spieëls van haar ouma se kas gefassineer is, hoe sy die eggo wou gryp en begryp. Die verband tussen ken en sintuiglike waaneming, die direkte ervaring van die werklikheid vir die karakters en verteller, die voel van die Syn, die bestaan aan die eie persoon, speel in albei verhale 'n prominente rol. Die verteller wat hier as 'n masker van die skryfster gesien kan word, bly soek en soek na die sin en die waarheid van dinge. Dit is nie net belangrik om te probeer uitvind wat dinge beteken nie, maar ook om te probeer uitvind hoe daar tot antwoorde gekom kan word.

\section{4 'n Ontsag vir die verwikkeldheid van die lewe}

Die skryfster bely ook openlik haar ontsag vir die verwikkeldheid van die lewe: die skrywer moet altyd selekteer en vereenvoudig, maar "daarmee ... sáám ... verloor hy nooit die basiese verwikkeldheid van dinge uit die oog nie" (Gesprekke, 3:73). Een van die opvallendste eienskappe van Grové se verhale is dat dit so dig en kompleks geskryf is, dat sy die kompleksiteit altyd weer byhaal en deur 'n soort opstapelingstegniek steeds die hele problematiek in die oog wil hou - 'n skryf- en denkwyse wat na hierdie oortuiging teruggevoer kan word

So word verhaalgegewens, kommentaar van die verteller en allusies saam gebruik om die leser met die totale problematiek te konfronteer:

Hierdie wrede spieëls kaats en kaats weer, kaats terug! Maar waar begin alles en eindig dit? Lyding, pyn en dood, pasgebore kinders, te vroeg gebore kinders, onteerde en dooie kinders, agterlike kinders! Wat is die mens? Hoe rooi keer die beelde terug en open onmeetlike ruimtes van pyn en eensaamheid. Hang daar lakens voor en bedek dit ganslik. 
So het ek my dit nie voorgestel nie toe ek as dogtertjie voor my grootmoeder se spieël gestaan het. Dit was bloot spel: 'n laatlamkind se vennaak om die drie spieëls só heen en weer te laat swaai dat jy self en alles om jou meer word en meer en jy jou naderhand verbeel jy hou die oneindigheid in jou hande vas (In die kamer, p. 55)

Die kind voor die spieël, die kwessie van lyding, die literêre spel en die verhaal self word saamgebind in die kommentaar van die verteller:

Onthou u die Elizabethaanse tragedies met hulle vyf bedrywe, en teen die einde lê 'n hele verhoog besaai met sterwendes en dooies, 'n hele oes.

In hierdie stories voel dit my ook al na 'n oormaat van afgestorwenes. Maar waar die baie sterftes in die Renaissancetreurspele die doel van 'n huis- of paleisskoonmaak gedien het ... het ek nie 'n benul van wat die uiteindelike betekenis van die menigvoudige ellendes in my verhale is nie. Hulle is net.

Al wat 'n mens opmerk, is: A weerkaats $B$, en $C$ verskyn ook in die glas. B is $C$ se komplement en $D$ weer $C$ se supplement. Maar waarom dit gaan en hoe dit moet eindig, al die bloed en die swaarkry. Net 'n kwessie van spieël en weerspieël, toeval, noodsaak of bloot die maak van 'n literêre patroon? (In die kamer, p. 57).

\subsection{Die bemoeienis met wat waar is}

Die bemoeienis met die waarheid is in 'n sekere sin dié deurlopende tema in Grové se werk. In die verhaal "Die Betlehemster" is dit al so duidelik hoe leuen en waarheid ineengestrengel is, dat geen mens waarheid en leuen uitmekaar kan ken nie. Die kind wat glo dat daar oor haar pa leuens vertel word, moet uitvind dat dit die waarheid is. Sy wil nie glo dat haar pa by ' $n$ ander vrou kuier nie en sy het die vaste voomeme om altyd die waarheid te praat. Wanneer sy egter in die ander vrou se huis beland, kom sy tot haar eie ontsteltenis agter dat sy iets begryp van haar pa se verhouding met die ander vrou. Sy sien dat daar by hierdie mens warmte en vrolikheid is wat by haar ma ontbreek. Uiteindelik vertel sy 'n leuen om haar ma teen die waarheid te beskerm en so verbeur sy die ster wat sy met absolute eerlikheid sou kon verdien. Sy verbeur ook haar kinderlike onskuld en die vertroue dat waar en vals duidelik onderskeibaar is.

Die problematiese verhouding tussen waarheid en leuen word die basiese tema in Die kêrel van die Pêrel wat as subtitel het Die anatomie van 'n leuenaar. Die eindelose ontleding van die verwikkeldheid van die lewenspatrone in In die kamer is ook 'n soeke na die waarheid, die sin, die betekenis van gebeure soos dié waaroor die verhaal gaan. Wat lê eintlik daar agter? Waarom gebeur dit? Hoe is dit te verklaar? Hoe moet dit beskryf word om die waarheid daarvan vas te vang? Is dit hoegenaamd moontlik? En kan dit alles uiteindelik begryp word? 
Grové (Gesprekke, 3:75) stel dit self so: "Ja, en ek is beslis onder die indruk van die onagterlıaalbaarheid van die waarheid. Ek soek byna krampagtig na iets wat jy onomstootlik die waarheid kan noem ... Ek sou die waarheid soos 'n kewer met my pen wou vasdruk." Omdat die kunstenaar nie die volle waarheid het nie, bly sy soek en daarom vind sy dit onvanpas dat mense by die kunstenaar 'n soort verlossende woord soek: "Dit lyk my, vandat tradisionele godsdiens sy houvas op soveel mense begin verloor het, soek hulle na 'n soort profeet, ag, byna 'n soort Messias in die kunstenaar ... (so)dat die kunstenaar ingedwing word in 'n rol waartoe hy glad nie opgewasse is nie, dit is nie sy funksie om Messias te wees nie."

Dit gaan dus vir die kunstenaar om die soeke en nie om die antwoord nie, veral nie daarom om 'n allerantwoord te probeer verskaf nie.

\subsection{Vryheid bly 'n onbereikbare ideaal}

Die skryfster glo dat vryheid 'n onbereikbare ideaal is en bly, vir die kunstenaar en ook vir die mens in die algemeen. Sy sluit die gesprek (Gesprekke, 3:77) soos volg af:

Nee, wat die vryheid betref, en nie net die sogenaamde vryheid van die kunstenaar nie, vra ek my dikwels af: is die swaar aksent wat vandag op die vryheid gelê word, die totale vryheid, vryheid teen elke prys, nie 'n uiting van desperaatheid nie? Vir die moderne mens is die dood die einde, en nou lyk die sug na vryheid vir my na 'n soort wanhoopspoging om die dood te ontvlug. Want hoe vry jy ook al is, op elke denkbare terrein - religieus, eroties, juridies - uiteindelik is daar die onverbiddelike wet van die sterwe. Dít bind almal en alles. Iemand het op 'n keer gesê: Hoe kan 'n mens vry wees as hy 'n duisend voorouers het? Ek sou wou sê: Hoe kan 'n mens vry wees as hy moet sterf?

Die karakters in die Die kêrel en In die kamer wil telkens graag hulle lewens in 'n rigting stuur. Elwiena wil so graag glo dat daar mooi en grasievolle dinge in die lewe is en brand haar vinger oor die kers om haar drome en GT se leuens tot waarheid te besweer. Net soos sy die waarheid (dat GT naamlik 'n absolute leuenaar is) moet aanvaar, moet sy later ook haar kind se ongeneeslike siekte, sy dood en Brink se selfinoord aanvaar. Sy kan dus nie van die werklikheid ontsnap nie. Op dieselfde wyse loop die karakters in In die kamer hulle telkens teen onontkombaarhede vas: Petrus kry wel 'n plaas, maar nooit 'n erfgenaam nie, Marta Koorts moet saamleef met die kind wat bloedskandelik by haar vertraagde dogter verwek is en Charlotte staan herhaaldelik met ontrouheid en dood gekonfronteer. Al die karakters strewe na geluk en vervulling, maar die onvolkomenheid van die lewe staan vas en die dood is en bly die uiteinde. 
Die gesprek waarna ek vroeër verwys het, het plaasgevind in 1973, 'n volle tien jaar voordat Die kêrel van die Pêrel verskyn en 16 jaar voor die verskyning van In die kamer was ' $n$ kas. Die eise en die ideale wat die skryfster vir haarself stel, die siening van haar werk en ook die erns waarmee sy haar taak as skrywer bejeen, die eerlikheid waarop sy aandring in die ondersoek van die verskynsels van die lewe, is dus vir haar meer as 'n verbygaande literêre eksperiment, dit is eerder 'n lewenswyse. (In 'n onlangse gesprek - einde 1995 - het sy bevestig dat hierdie dinge vir haar steeds van kardinale belang is, selfs meer as vroeër.)

Daar spreek 'n soort erns uit hierdie sieninge wat meestal met godsdienstigheid in verband gebring word. Ten spyte hiervan, is daar in haar werk baie min vermelding van godsdiens as sodanig. In die laaste twee werke word daar glad nie direkte verbande tussen die problematiek van die karakters en religie getrek nie. Vandaar Olivier se uitspraak: "Bybelse resonansies sonder Bybelse troos."

Maar die skrywer is nie die Messias nie, sê Grové. Die skrywer het nie al die antwoorde nie. Die skrywer het wel die vrae, die skrywer het wel die soeke. Die vraag is: hoef die literatuur noodwendig antwoorde van watter aard ook al, te gee?

\section{Fokalisasie en visie}

Vir my is die bepalende eienskap van Henriette Grové se werk die manier waarop daar na die lewe en sy problematiek gekyk word. Die visie waarmee die verhaalstof geselekteer, georden en aangebied word, kan in hierdie werk nooit deur die leser geïgnoreer word nie.

Nou is die teoretiese konsep waannee die kykfunksie in die narratiewe teks omskryf word, fokalisasie. 'n Mens sou egter gewis nie kon volstaan met die beskrywing van fokalisasie as intern of ekstern of personasiegebonde nie, want afgesien van die verskillende vlakke van fokalisasie, van karakters en verteller en implisiete outeur, het 'n mens met 'n grondliggende en totale visie te make, waar visie hier ook die manier van kyk van die abstrakte of implisiete outeur aandui.

Mieke Bal (1980:108 e.v.) definieer fokalisasie as die verhouding tussen die waarnemer en dit wat waargeneem word. Wanneer 'n mens egter gaan kyk na Genette (1980:160 e.v.) se oorspronklike verduideliking van die term, blyk dat hy die term fokalisasie gebruik as onderdeel van die kategorie van narratiewe modaliteit. Net soos wat die vorm van 'n werkwoord die verhouding tussen die subjek en die handeling wat in die werkwoord beskryf word, kan aandui, speel modaliteit in die verhalende teks 'n bepalende rol. Dit gaan dan hoofsaaklik om die aard van die verhouding tussen die vertelde (histoire) en die vertelhandeling. Genette sluit onder narratiewe modaliteit in sowel die afstand tussen vertelinstansie en vertelde inhoud (mimesis of diëgesis) as perspektief. Perspektief 
Heilna du Plooy

verdeel hy egter weer in twee onderafdelings, naamlik fokalisasie, die oriënterende perspektief wat die verhaal bepaal, en voice wat as die "narrating situation" omskryf word

Die standaardomskrywings van fokalisasie soos hierbo gegee, verskaf nie 'n adekwate raamwerk om die aard van 'n bepaalde soort kyk of waarneming te omskryf nie. Rimmon-Kenan (1983:77 e.v.) probeer die skopus van die term fokalisasie uitbrei deur te stel dat fokalisasie nie net 'n visuele begrip is nie. Sy toon dan aan dat daar verskillende fasette van fokalisasie onderskei kan word, naamlik ' $n$ perseptuele, psigologiese en ideologiese faset, wat telkens die moontlikhede van 'n interne of eksterne fokalisasie bepaal

In 'n resente artikel oor fokalisasie, waarin hy sekere hipotetiese vorme van fokalisasie ondersoek, sluit David Henman (1994:230 e.v.) aan by Genette deur klem te plaas op modaliteit as die bepalende faktor in fokalisasie. Die strak sistematiese kategorieë van fokalisasie word gekritiseer as ontoereikend ondat fokalisasie veel meer omvat as 'n eksteme of inteme posisie al sou perseptuele, psigologiese en ideologiese fasette 'n rol speel

Herman (1994:231) omskryf fokalisasie soos volg:

Ways of focalizing a story can thus be redescribed as the narrative representation of propositional attitudes, i.e. modes of focalization encode into narrative form various kinds of epistemic stances that can be adopted towards what is being represented in a narrative

Hy stel voor dat die kategorisering van verskillende soorte fokalisasie in "blokke", vervang word met 'n glyskaal van moontlikhede: "we can interpret types of focalization as scalar phenomena, ranked incrementally along a continuum of epistemic modalities" (Herman, 1994:231). Herman (1994) betoog in hierdie artikel dat fokalisasie 'n belangrike aanduiding is van die intensionele betekenis (Sinn) van taal teenoor die referensiële betekenis (Bedeutung) van taal en dat kennis van die semantiek in grammatika en linguistiek 'n mens hierin moet help. Fokalisasie word beïnvloed en bepaal deur die epistemologiese posisie van waarneming en die proposisies wat in die formulering van die waarneming gebruik word, dra die epistemiese implikasies van die vertelling aan die leser oor.

Met so 'n siening kan 'n mens fokalisasie op 'n verskeidenheid maniere onderskei en omskryf, aangesien die manier van kyk na die wêreld (die werklike wêreld en fiksionele wêrelde - inoontlik, fantasties absurd, of wat ook al) op grond van die episteem waarbinne gedink en geleef word, 'n oneindige aantal variasies kan aanneem (vgl. Ryall, 1992:528-553). 


\section{Mitiese vrae}

As 'n mens 'n beskrywing wil gee van die manier van kyk van die abstrakte outeur (die skrywerspersoonlikheid soos wat dit uit die oeuvre van die skrywer aan lesers bekend word), van wat ek noem die visie en wat omskryf kan word as die epistemologiese implikasies van die fokalisasie in ' $n$ wyer sin, in die verhale van Henriette Grove, kom die ooreenkoms met die uitgesproke poëtika van die skryfster duidelik na vore. Die manier van kyk sluit aan by 'n lewensbeskouing wat grondige vrae vra oor die bestaanswerklikhede en eksistensiële problematiek van die mens. Dit laat die vermoede ontstaan dat 'n mens hier met literatuur te make het wat verwant is aan die mitiese.

As 'n mens aanvaar dat ' $n$ taalteks in sy proposisies wel iets reflekteer van die epistemiese posisie van die fokaliserende instansie (hetsy dit die outeursinstansie, die verteller of ' $n$ karakter is), dan is die volgehoue konsentrasie op die temas hierbo aangetoon (temas wat struktureel en talig beklemtoon word), 'n bewys daarvan dat dit in hierdie tekste gaall om 'n bemoeienis met 'n bepaalde soort vraag. Dit gaan om vrae wat nie uit die praktyk van die lewe beantwoord kan word nie, vrae wat nie met wetenskaplike feite of gegewens beantwoord kan word nie.

Vir hierdie vrae kan antwoorde gesoek word in religieuse konsepte

Noukeurig beskou, vind $\mathrm{ek}$ in die verhale nie 'n sinnelose pessimisme nie, nie 'n ondeurdagte flirtasie met die donker kant van die lewe nie, maar 'n soeke, in absolute gestrooptheid, met ' $n$ byna ongenadige eerlikheid, na ' $n$ noukeurige deurskouing en formulering van dié soort menslike lyding wat 'n mens elke dag om jou sien: die oonnaat daarvan, die veelvuldigheid daarvan, die onverklaarbaarheid daarvan. Ligte sentimentele troos, 'n utopie in woorde kan nie aan die omvang en diepte van die menslike dilemma laat reg geskied nie. Ontdaan van alle illusie en pretensie, moet die eksistensie beskou en beskryf word sodat die allerrelevantste vraag by implikasie gevra word. En dit is 'n mitiese vraag.

Ek gebruik die term mities hier in 'n spesifieke betekenis en wel soos dit deur André Jolles omskryf is in sy bekende werk Einfache Formen (1956). Jolles beskryf nege Geisiesbeschaftigungen, geestesaktiwiteite wat so dwingend in die kollektiewe menslike psige funksioneer dat dit deurlopend in taalvorme en -strukture en ook in die literatuur tot uiting kom. Hy gee 'n spesifieke omskrywing van die konsep mite. Volgens hom is die mens se behoefte aan antwoorde op metafisiese vrae die geestesaktiwiteit waaruit die mite en mitiese aktiwiteite voortvloei. Mense wil graag weet waar dinge vandaan kom, wat die sin en betekenis van dinge is (al is die antwoord dat daar geen sin of betekenis is nie). Die mens soek altyd na die onsienlike magte agter die sigbare dinge en dit is in hierdie verband baie belangrik om te begryp dat die opvatting dat daar niks 
Heilna du Plooy

agter die oppervlakkige verskyningsvorme lê nie, slegs een bepaalde resultaat is, 'n antwoord op dieselfde vraag waarvoor 'n religieuse antwoord gegee sou kon word. Dit gaan hier om die menslike behoefte daaraan on hierdie soort vrae te vra. En mites is die verskillende antwoorde wat gebied word op hierdie metafisiese vrae (Jolles, 1956:80).

Waar die groot religieë van alle tye telkens 'n bepaalde stel antwoorde gee op die mens se vrae na die onsienlike magte wat die wêreld beheers en stuur en die sin daarvan, hoef die skrywer dit nie te doen nie. Die skrywer is immers geen god nie en die Christelike skrywer juis nie. Maar die skrywer en veral die Christelike skrywer kan wel die vrae vra, selfs impliseer dat dit die enigste relevante vrae is om uiteindelik te vra.

\section{Konklusie}

Hoewel ek geensins die etiket Christelike skryfster, of Christelike literatuur aan Grové en haar werk wil heg nie, is haar verhale myns insiens die uitgebreide fornulering en toeligting van vrae wat eintlik net deur mitiese/religieuse antwoorde beantwoord kan word. Ek sou die verhale dus as mitiese vraagstelling wou tipeer en ek doen dit spesifiek in hierdie algemene terme omdat die spesifieke antwoorde van 'n bepaalde dogma nie in die tekste aangedui word nie. Die religieuse strekking van die vraagstelling kan nie ontken word nie en die verband met vrae en probleme wat tradisioneel in die tekste van die Christelike godsdiens voorkom, kan ook nie maklik misgekyk word nie.

Dit gaan in die verhale gewis nie daarom on antwoorde te verskaf op die "waarom" van lyding en dood nie: daarop gee die religie self antwoord. Die tekste is gemoeid met die is van lyding en dood. Die roman is nie met eskatologie besig nie, maar met die syn.

Die lewe is erg, menslike lyding en ellende herhaal sigself eindeloos. Die liefde blom momenteel, maar die dood is die seker uiteinde. In die eerlikheid waarmee hierdie tekste die uiteindelike konflik van die mens se bestaan, sy blote eksistensie deurskou, setel die gesag van die verhale. Wat hier en nou is, moet gehanteer word: daar kon imıners nog nooit in enige religieuse raamwerk gesê word dat mense nie behoort of nie sal swaarkry nie. Maar die mens moet dit wat vir hom voorbestem is, deurleef: dit is sy dilemma dat hy nie altyd weet hoe nie en tog moet.

Die verhale van Henriette Grové spreek van 'n geestelike volwassenheid wat anderkant oppervlakkige bespiegeling en geykte troosfonmules lê. Dis uiteindelik 'n lament oor die menslike kondisie wat tot in sy diepste verborgenhede aangetas is. Haar verhale is immers nie net ' $n$ klaaglied oor menslike lyding en dood, oor 
onvernoë en gebrek aan insig nie, dis ook 'n eerbetoon aan menslike uithouvermoë.

Om as skrywer so onbevrees deur die diep en donker plekke te loop waarheen die verhaal jou lei en die leser op hierdie pad mee te neem, om in die toe-eiening van die soms gevaarlike verantwoordelikheid sonder skille op die oë te kyk en te probeer wéét - al is die weet soms juis dat jy nie in staat is om te weet nie of nie in staat is om die wete te verdra nie: hierdie soort skryf is vir my 'n religieuse aktiwiteit op sigself.

\section{Bibliografie}

BAL, Mieke. 1980. De theorie van vertellen en verhalen Muiderberg: Coutinho.

BEARDSLEY, M. 1958. Aesthetics: Problems in the philosophy of criticism New York Harcourt Brace \& World

BRINKER, M 1993 Theme and interpretation ( $m$ Sollors, Werner ed. The return of thematic criticism Cambridge, Massachusetts : Harvard University Press. p. 21-37.)

DU PLOOY, Heilna 1990 Die polifoniese gesprek - intertekstualiteit as leesmodus. Stilet, II(2) 1-14, Sept

DU PLOOY, Heilna 1991. Rondom die rympie. Tydskrif vir Letterkunde, XXIX(1):60-68, Febr.

GENETTE, Gerard. 1980 Narrative discourse Oxford : Basil Blackwell

Gesprekke met skrywers 3. 1973 Henriette Grové in gesprek met Elize Botha. Kaapstad Tafelberg.

GROVE, Henriette, 1983. Die kêrel van die Pêrel Kaapstad : Tafelberg

GROVE, Henriette 1989 In die kamer was 'n kas Kaapstad : Tafelberg

HERMAN, David. 1994. Hypothetical focalization Narrative, 2(3) 230-253, Oct

JOLLES, André 1982 (1930). Einfache Formen Tubingen: Max Niemeyer Verlag

OLIVIER, Gerrit 1990 Die bloed van die mensdom. Vrye Weekblad, Jan. 26.

RIMMON-KENAN, Shlomith 1983. Narrative fiction-Contemporary poetics. New York Methuen.

RYAN, Marie-Laure 1992. Possible worlds in recent literary theory Style, 26(4):528-553, Winter

SOLLORS, Werner ed. 1993. The return of thematic crititicism Cambridge, Massachusetts Harvard University Press. 